\title{
QUEEN'S
UNIVERSITY
BELFAST
}

\section{The views and experiences of lesbians regarding their mental health needs and concerns: qualitative findings from a mixed-methods study}

Brown, M., \& Mccann, E. (2020). The views and experiences of lesbians regarding their mental health needs and concerns: qualitative findings from a mixed-methods study. Perspectives in Psychiatric Care. https://doi.org/10.1111/ppc. 12498

Published in:

Perspectives in Psychiatric Care

Document Version:

Peer reviewed version

Queen's University Belfast - Research Portal:

Link to publication record in Queen's University Belfast Research Portal

Publisher rights

Copyright 2020 Wiley. This work is made available online in accordance with the publisher's policies. Please refer to any applicable terms of use of the publisher.

\section{General rights}

Copyright for the publications made accessible via the Queen's University Belfast Research Portal is retained by the author(s) and / or other copyright owners and it is a condition of accessing these publications that users recognise and abide by the legal requirements associated with these rights.

Take down policy

The Research Portal is Queen's institutional repository that provides access to Queen's research output. Every effort has been made to ensure that content in the Research Portal does not infringe any person's rights, or applicable UK laws. If you discover content in the Research Portal that you believe breaches copyright or violates any law, please contact openaccess@qub.ac.uk. 
THE VIEWS AND EXPERIENCES OF LESBIANS REGARDING THEIR MENTAL HEALTH NEEDS AND CONCERNS: QUALITATIVE FINDINGS FROM A MIXEDMETHODS STUDY

\section{Authors:}

Edward McCann PhD RN RNT SFHEA Trinity College Dublin, School of Nursing and Midwifery, Dublin, Republic of Ireland

Michael John Brown PhD RGN RNLD SFHEA Queen's University Belfast, School of Nursing and Midwifery, Belfast, Northern Ireland

Word Count: 5029

\section{Correspondence:}

Dr Edward McCann

Trinity College Dublin

School of Nursing and Midwifery

24 D'Olier Street

Dublin 2

Ireland

E-mail: mccanned@tcd.ie

Phone: +35318964161

ORCID: https://orcid.org/0000-0003-3548-4204

Conflict of interest statement: The authors report no actual or potential conflicts of interest 


\section{ABSTRACT}

Purpose: The aim of this paper is to report the specific views and experiences of lesbians and identify their distinct mental health issues and concerns.

Design and methods: A mixed-methods design with surveys and individual interviews was utilised. The data were thematically analysed.

Findings: The key themes were: (i) enabling service access, (ii) person-centred support, (iii) models of care, (iv) community presence and participation, and (v) future aspirations for mental health services.

Practice implications: The study results inform and develops the understanding of the issues that impact upon the mental health and well-being of lesbians. The implications for mental health practice are discussed.

Keywords: Lesbian, nursing, mental health, psychosocial needs, social inclusion, human rights, education 


\section{INTRODUCTION}

A developing body of international research evidence exists regarding LGBT populations (Smith et al. 2018; Caceres et al. 2019; McCann \& Brown 2019a). However, health-specific research focusing on LGBTQ+ populations is a neglected area (Hickson et al. 2016; Hafeez et al. 2017; Younas 2019). LGBTQ+ subgroups within many of the existing research studies are often perceived as homogenous and indistinct entities, rendering it difficult to identify individual needs and service requirements. Studies that focus specifically on the LGBTQ+ subpopulations are required, thereby recognising and identifying the unique and diverse experiences of particular groups, including lesbians (LaVaccare et al. 2018; Snyder, 2019)

In the UK, current evidence suggests that 93.2 percent of people identified as heterosexual (Office for National Statistics 2017). In the United States (US), a Gallup poll concluded that $4.5 \%$ of adult Americans identified as LGBT with $5.1 \%$ of women identifying as LGBT, compared with $3.9 \%$ of men (Gallup 2017). Another survey estimated that $0.6 \%$ of U.S. adults identify as transgender (Williams Institute 2016). While this evidence is useful regarding LGBT+ populations as a whole, there is a lack of demographic figures regarding lesbians, as a distinct group.

Lesbian is the term most widely used to describe sexual and romantic attraction between females. A clear definition is necessary to conceptualise the health implications for lesbians. However, there is no internationally recognised definition of lesbian. The term can be used to denote women who have sex with women; women who self-identify as lesbian; and women whose sexual preference or desire is towards women. Some research studies have included women who self-identify as bisexual when defining lesbians (Institute of Medicine Staff 1999).

Lesbians experience significant challenges regarding their physical and psychological wellbeing. A systematic review addressing comparisons between heterosexuals and lesbian and 
bisexual women identified disparities in physical health conditions including obesity, arthritis and cardiovascular disease. Further research is required to identify the factors contributing to these health disparities (Simoni et al. 2017). Another systematic review highlighted significant issues related eating disorders in lesbians including binge eating, purging and low body satisfaction, compared to heterosexual women (Meneguzzo et al. 2018).

Compounding the physical challenges lesbians can experience specific psychosocial consequences of discrimination, prejudice, and victimisation (Kelleher 2009; Toomey et al. 2018; Bostwick et al. 2019). There is a strong association between sexual minority status and poor mental health outcomes (Kertzner et al. 2009; Steele et al. 2017), with theories developed to explain the prevalence of mental health issues among sexual minority groups, including lesbians. One example is the minority stress model (Meyer 2003), that hypothesises that adverse mental health experiences are a result of stress that originates and is influenced by discrimination, stigma and victimisation faced by people from sexual minorities (Lea et al. 2014). Existing research studies investigating psychological distress, mental health and wellbeing among sexual minority women (SMW) found that lesbian and bisexual women were more likely than heterosexual women to report alcohol problems, increased drug use and depression (Balsam et al. 2005; Drabble et al. 2005; McCabe et al. 2009; Trocki et al. 2009; Hughes et al. 2010; Andersen et al. 2014; Dworkin et al. 2018; Veldhuis et al. 2019). Depression is a major public health issue for women in the general population, with $10 \%$ of women in the United States (US) reporting major depressive symptoms (Pyra et al. 2014). In one study, $42 \%$ of lesbians reported major depressive symptoms, compared with $27 \%$ of the heterosexual women surveyed (Bostwick et al. 2010). Sexual minority women were also more likely to seek treatment for substance misuse and mental health issues, such as depression and anxiety disorders (Jessup \& Dibble 2012; Kwon 2013; Drabble et al. 2013). Other subgroups, 
such as Black lesbians experience further discrimination due to their gender, race and sexual orientation (Balsam et al. 2015; Sabin et al. 2015).

Victimisation concerns, including physical and sexual abuse, occurring in child or adulthood, are correlated with poorer mental health experiences in later life (Bonomi et al. 2007; Edwards et al. 2015; Smith et al. 2017; Szalacha et al. 2017; Bostwick et al. 2019). For sexual minority women, compared to heterosexual women, victimisation experiences were significantly higher in adulthood (Drabble et al. 2013), adolescence (Friedman et al. 2011), and childhood (Schneeberger et al. 2014). Despite the apparent challenges to an individual's mental health and well-being, many lesbians develop positive coping responses and demonstrate resilience in the face of stress and adversity, thereby impacting positively on their mental health and well-being (Kwon 2013; Lyons 2015; Meyer 2015; de Lira \& de Morias 2018). While recognising the importance of enabling the development of resilience and protective factors, some women will experience mental ill health, necessitating access to mental health assessment, treatment and support. Ideally, mental health services should be accessible and person-centred. However, the prevailing heteronormative culture within healthcare continues to present challenges to the provision of responsive holistic care and supports (Soinio et al. 2019).

\section{Aims}

The aim of the study was to identify and present the issues and concerns for lesbians and present recommendations to improve the mental health and well-being.

\section{METHODS}

The wider research study, involving LGBT+ participants, investigated their mental health experiences and needs in the Republic of Ireland using a mixed-methods research design. The data set was completed in 2014. The study was an exploratory design utilising mixed-methods. Both quantitative and qualitative data were collected using a survey instrument $(n=125)$ of 
which $33 \%$ ( $n=41)$ self-identified as lesbian. This paper reports the qualitative element of the survey as self-reported by the 41 lesbians and the findings from qualitative in-depth interviews of the views and experiences of lesbians $(n=7)$. The lesbian-specific qualitative data was extracted and analysed separately by the research team to enable the analysis and identification of their unique views and experiences.

\section{Ethics statement}

The study was the subject of ethical review and approval by the relevant ethics committee. All study participants provided independent informed consent. Throughout the study, all ethical and governance processes were adhered to. In recognition of the potential for distress due to participating in the study, details of mental health support organizations and helplines were provided to study participants.

\section{Study questions}

1. What are the views and experiences of lesbians regarding mental health concerns?

2. What are the mental health support needs of lesbians?

\section{Sampling and inclusion criteria}

A convenience snowballing sampling strategy was utilized in recognition that the target population can be hidden and therefore difficult to reach (Flannigan \& Hancock, 2010). People were invited to participate (i) if self-reported as lesbian, (ii) had used mental health service in the past 5-years in Ireland and (iii) were aged 18 years and over.

\section{Data collection and recruitment}

The study was conducted in the Republic of Ireland among adults identifying as lesbians who had experience of mental health services in community and inpatient settings. The survey and interview schedule were piloted and minor alterations made and distributed. Forty-one $(n=41)$ lesbians completed the on-line survey. Following this a further seven $(n=7)$ consented to an in-depth face-to-face qualitative interview. These interviews were tape recorded and lasted 
between 45 minutes and 60 minutes and were carried out by an experienced post-doctoral researcher.

A number of diverse approaches were adopted within the recruitment strategy. The first step involved sending information about the study to LGBT and mental health organizations across the Republic of Ireland. The packet included details about the study, inviting the organizations to disseminate the information through their social media outlets, via newsletters, posters and leaflets, and providing hardcopies of the survey instrument to interested participants. The second approach involved emailing mental health and LGBT organisations across the country inviting them to forward information about the study and the survey link on to their electronic contact lists. Lastly, information about the study was provided to key LGBT organizations across Ireland to post and disseminate via their social media pages.

\section{Data analysis}

To ensure anonymity, pseudonyms were allocated to all participants in both the qualitative survey and in-depth interviews. Two researchers analysed the data set systematically using the recognized principles of thematic analysis to identify the emerging themes across and within the participant responses. Each transcribed interview response was analysed individually and collectively by the researchers to enable the identification of the key themes (Clarke \& Braun 2017). To support the rigor of the of the data set, QSR NVivo 11 software (QSR International 2015) was used throughout.

\section{Validity, reliability and rigour}

To ensure academic rigor in qualitative data analysis, the use of comprehensive methods of data collection, analysis and synthesis were required. These approaches were utilized within the current study as part of the quality assurance processes adopted and applied to ensure the validity, reliability and credibility of the findings and recommendations (Lincoln \& Guba 1985; Noble \& Smith 2015). To ensure rigour in these processes, the research team individually and 
collectively analysed the data by checking, cross-checking and agreeing the final themes. By rigorously adhering to these approaches, the psychosocial experiences and support needs of the lesbians who participated in the study were identified and a series of evidence-based recommendation presented (Graneheim et al. 2017).

\section{RESULTS}

The study involved forty-one $(\mathrm{n}=41)$ lesbians who completed an on-line survey, providing quantitative and qualitative data. A further seven $(n=7)$ lesbians from the larger sample of forty-one took part in in-depth qualitative face-to-face interviews. The ages of the participants ranged from 18 to 64 years. In terms of psychiatric diagnoses, the self-reported conditions were depression $(50 \% ; \mathrm{n}=32)$, anxiety disorders $(27 \% ; \mathrm{n}=11)$, eating disorders $(24 \% ; \mathrm{n}=10)$, psychoses $(12 \% ; n=5)$, gender identity disorder $(10 \% ; n=4)$, post-traumatic stress disorder $(7 \%$; $\mathrm{n}=3)$ and obsessive compulsive disorder $(5 \% ; n=2)$. A total of $49 \%(n=20)$ of respondents reported co-morbid mental health issues with the most common being depression and anxiety. From a treatment perspective, $98 \% ;(n=40)$ of respondents were prescribed psychiatric medication. The most commonly reported psychotherapy was cognitive behavioural therapy $(39 \% ; n=16)$ followed by family therapy $(10 \% ; n=4)$, mindfulness $(10 \% ; n=4)$ and counselling $(7 \% ; n=3)$. The treatment settings were community outpatients $(68 \% ; n=28)$, hospital inpatient $(5 \% ; n=2)$, and a combination of hospital inpatient and community outpatient $(27 \%, \mathrm{n}=11)$ (see Table 1).

Following analysis of the qualitative data, five themes emerged: (i) enabling service access, (ii) person-centred supports, (iii) models of care, (iv) community presence and participation, and (v) future aspirations for mental health.

\section{Enabling service access}


It is recognised that to provide mental health assessment, treatment and support, a positive, trusting therapeutic relationship needs to be established and maintained with health professional. Experiences were variable and for some their experiences were not positive, which they felt had a detrimental effect upon their confidence in the health professional to work with them to meet their individual needs. Some participants experienced mental health professionals who attributed the patient's presenting situation in the context of their sexuality, with some going as far as to suggest that by 'becoming heterosexual' and 'finding a man' would be 'the solution' to all the mental distress issues, even when seemingly unrelated:

I was really depressed... then I saw the psychiatrist... when I did say something about my sexuality to him, he was kind of like "oh but you're so pretty"... like "oh but you're beautiful, you'll find a man and everything will be fine for you'. I was like, seriously!... $(\mathrm{P} 2)$

Some participants experienced mental health professionals with poor attitudes, disinterest and apathy that impacted on their ability to be open and share their experiences and seek potential solutions to their mental health concerns:

....it would be a huge deterrent...even to coming out, I would think... professionals treating you unpleasantly, then who else is going to? So, I feel that it could be very detrimental to people's mental health, to encounter a poor mental health professional with questionable attitudes and values towards gay and lesbian people... (P8)

For others, they experienced mental health professionals who provided a positive therapeutic environment in which deeply personal information, including details related to sexuality could be safely disclosed and shared: 
I was lucky to get somebody who was understanding and compassionate in terms of my sexuality...it would be fairly hindered, because I wouldn't have been able to be as free.... I wouldn't have been able to talk freely about the things that were bothering me, including stuff about being a lesbian (P35)

For a participant with mental health issues, a physical disability, and who was also lesbian, the feeling of not being fully listened to and understood remained a lasting memory of her experience of services:

I started to use the mental health service, and the counsellor I got understood about the lesbianism bit, but didn't understand about the disability bit, and that was huge for me, absolutely huge...she was kind of dismissive, and I felt she didn't believe me. It actually took me about three years to get the answers about my concerns about my mental health, disability and being a lesbian, and that was really important to me, but it took a long time. (P12)

\section{Person-centred supports}

Within all health services there is a strong focus on person-centred care and support, where identifying and understanding the needs and concerns of the individual is at the heart of therapy, care and support. This is particularly important in mental health services where the concept of respectful, inclusive and co-produced therapeutic relationships and supports are fundamental to achieving positive treatment outcomes:

When you're depressed, you tend to talk yourself in circles and think yourself in circles, and it's very hard to get yourself out of it...whereas talking with a professional, you can find the reasons you're thinking this way and try find solutions...and it can be very helpful, you know, get yourself out of a mental rut... (P18) 
While it was stated by participants that this is the ideal situation, for some there were education and practice development issues that needed to be addressed to ensure mental health professionals possess the necessary knowledge and skills that go beyond mental health conditions:

Provide education to mental healthcare staff regarding lesbian issues - one counsellor seemed to believe that sexuality was changeable, they didn't encourage me to change or say I should, but the fact that they felt your sexual orientation was changeable made it feel like they were judging me, and made me uncomfortable (P5)

For one participant, there were assumptions and value judgements made by the assessing mental health professionals based on the decision to disclose information regarding her sexuality:

I would feel that if...I mentioned my sexuality, then they will kind of latch on to that as the core of the issue, 'oooh troubled....' when it really has absolutely nothing to do with that, like I am very comfortable with my sexuality, and I ...like I don't feel like it has had any impact on my mental health, but the assumption was made anyway with no checking (P17)

Some participants highlighted feeling comfortable with sharing their sexual identity with the mental health professional and expected it to be factored into the assessment of their situation, only to find it ignored, as though it had never been mentioned:

I don't really have an issue with disclosing my sexuality, but as I said, once it's disclosed and out there, it's not discussed and basically ignored as though it didn't happen (P11) 


\section{Models of care}

The model of care upon which mental health services are delivered need to be responsive to individual needs, adopting approaches that are inclusive and respectful. Central to the model of care is the need to ensure that mental health practitioners are skilled and competent by clearly demonstrating that their practice is built around equality, respect for diversity, empowerment and human rights. For some participants, there was the view that they would have been more comfortable accessing mental health services that were gender-specific:

Many women, including lesbians, prefer to access women-only support in a range of contexts, including for their mental health - this should be made available (P20)

Possessing the relevant knowledge and skills was viewed as essential to delivering a mental health service model that is reflective of the needs of lesbian patients. As one participant explained:

Changes are needed that's for sure. We need to have more people specialised working in this area... psychiatrists, psychologists, counsellors and nurses... they need to upskill along with changes in society, including those to do with sexuality (P6)

Developing a model of care that was built around empathy and understanding for the individual and unique needs of the patients was seen as critical by many participants. One participant highlighted that simply sharing their sexual identity with the mental health professional would not effective change if the model of care and the attitudes and values of the professionals working in the service were not aligned:

Staff should remember that it's the individual who requires the care. Think about it, "coming out" to the health worker may not be the "be all and end all". One clinical 
psychologist seemed to think that once you came out the world suddenly was a happier, nicer place - despite having acknowledged they had limited experiences with lesbian individuals. That needs to change for sure (P25)

A recurring issue highlighted by many participants related to the lack of treatment options available and the need for a review of the model of care to ensure that a full range of treatment modalities were available:

I do think other services should be available, if you want them, like there is no alternative to like going to a hospital every week for more medication and getting another prescription. Like no one's going to offer you like occupational therapy, or anything like that, and I think people would benefit from alternatives to medication. I think if there had been an alternative at certain points in my treatment, I would have been more than happy to try it, but I never got any (P22)

\section{Community presence and participation}

Ensuring that there is access to a range of community organisations and supports was viewed as important by many participants, as a means to enable community connection and the opportunity to access support. While it was recognised that significant strides have taken place over the past few years in Ireland, it was stated that more needs to be done to provide community support groups and networks across the country. Changes in legislation was viewed as playing an important role, however it was seen as only part of the solution, as detailed by one participant:

...you can have all the legislation in the whole wide world, but if the attitudes haven't changed, well then, that legislation is absolutely useless, because the implementors and 
enforcers have the attitudes, so where do you go with that? That needs to change too in my view $(\mathrm{P} 15)$

LGBT community organisations were viewed as helpful, by some participants, as a means to provide access to social networks and supports. Some community organisations were identified as requiring access to further training and practice development regarding the needs of LGBT people, including lesbians:

Training should be provided to women's organisations, such as Rape Crisis centres, refuges, etc, on sexual orientation as equalities group, to make sure they are providing appropriate services for all women who access them, not just straight women (P28)

Some participants were of the view that more work needed to be done outside of the larger cities to ensure that is access to LGBT support groups and networks:

...I can't even imagine what it's like to be a mentally ill lesbian person from the countryside, like I know my terrible experience has been trying to get support in our big capital city of Dublin (P40)

Wider representation of LGBT people and lesbians in campaign in schools, via social media and on television, was seen as necessary, for some, to help challenge assumptions and start to change attitudes.

\section{Future aspirations for mental health}

All participants had their own unique stories and journeys through mental health services. They were invited to make recommendation, based on their experience of services, how services could be developed and improved for the future. A diverse range of suggestions were 
made including improving access to mental health assessment and treatment options, providing further education and practice development of the needs of LGBT people, and lesbians more specifically. A common concern was the need to increase the treatment options available within publicly funded health services across Ireland to allow for increased access to therapeutic approaches, beyond medication, including the provision of and access to psychotherapies:

I would feel that they are still very archaic in their style of medicine and the treatments and supports on offer and also their way of dealing with young people in general but particularly with LGBT young people. I just think they have no clue about it really, they really, really need to come into the 21 st century and catch up quickly (P27)

A recurring issue highlighted by many participants related to the need to develop and provide education and practice development programmes regarding the care and support needs of LGBT people and specifically those experiencing mental distress:

Obviously, I think it would be great if people had more training, like when they were becoming doctors or nurses, like it would probably not take too long actually, it probably wouldn't be like that much of a stretch to get it sorted.....(P17)

The model of care and the provision of person-centred care was highlighted by many of the participants. Accessing mental health services that were designed and built around the needs of the diverse range of mental health patients, including lesbians and LGBT people was seen a necessary for the future.

You just want to be treated as normal, as an individual. it's not about any extra really, it'd just be about, being treated respectfully and listened to. You're going there for 
treatment you should get treatment you actually need and want irrespective of your gender and sexuality. They shouldn't affect anything (P8)

\section{DISCUSSION}

This study sought to determine the experiences and views of lesbians regarding their mental health issues and concerns and highlight key factors related to their distinct health and support needs. It is evident that lesbians experience poorer physical and mental health when compared to women in the general population (Toomey et al. 2018). Some of the most common mental health issues include depression, anxiety and substance misuse (Balsam et al. 2015; Veldhuis 2019). The findings from the current study are reflective of the existing international research evidence highlighting the frequency of mental ill health, prescribed medication use and service utilisation (Drabble et al. 2017; Soinio et al. 2019). For some participants, health service access was challenging with individuals expressing the need for supports and services that that are accessible, responsive and person-centred (Moore et al. 2017). Failure to address these issues leaves patients feeling vulnerable, excluded and further marginalised (Livingston et al. 2019). A significant issue in this study related to the over-reliance on psychiatric medications as the primary mode of treatment. Many highlighted the need for access to alternative treatment options, including psychotherapies. However, within Irish health services, regular access to such treatments appears limited, despite government policy directives (Department of Health 2006; Health Service Executive 2016). Central to all healthcare service delivery is the provision of assessment, treatment and supports that respond to the distinct needs of the individual and that are delivered by nurses and other health professionals who are knowledgeable, skilled and competent (Rowe et al. 2017; McCann \& Brown 2019b).

There is a strong focus within health services on health prevention and the promotion of positive mental health and well-being (Wahlbeck 2015). Access to social support through 
community networks and organisations are recognised as playing important roles in helping people to develop and maintain resilience, expand social networks and develop friendships and relationships necessary for positive mental health and well-being (Artiga \& Hinton 2019). In many countries, there have been significant legislative and policy developments that have resulted in the increased visibility and presence of LGBTQ+ people (World Health Organisation 2013). With this increasing visibility comes the need to ensure that health services and the professionals that practice within them, are equipped with the relevant knowledge, skills, attitudes and values necessary to deliver culturally competent, inclusive and responsive health care (Voss 2018; D’Emilio 2019).

Despite the clear policy focus on reducing inequalities and promoting health and wellbeing, lesbians requires a specific and sustained policy focus to ensure that their individual health needs are adequately addressed. While policy attention on LGBTQ+ health is welcome and necessary, the specific position of lesbians within this wider population presents particular limitations and challenges to the identification of their healthcare and psychosocial needs. There is a need to separate and research the sub-populations comprising the LGBTQ+ communities. This is required as research studies frequently draw the groups together under the wider 'rainbow umbrella' (Savin-Williams et al. 2018). The consequences of this research approach shift the focus from identifying the needs and concerns of lesbians and their specific support needs. Therefore, policies that are being developed need to ensure that the unique needs of all of the LGBTQ+ populations are individually reflected thereby ensuring that responses are more targeted and specific to the needs of the individual sub-groups. Given the evidence of the extent of the psychosocial needs of lesbians, there is an opportunity to ensure that policy initiatives, such as public health, primary care, sexual health and mental health, integrate and reflect the needs of lesbians. 
All patients want to be recognised as individuals receiving care that is person-centred and responsive to their particular situation and requirements (Merner et al. 2019). Health practitioners need to identify and be aware of lesbians within mental health services and ensure their identity is positively regarded and affirmed to enable the full expression of their sexuality. Comprehensive biopsychosocial assessments undertaken by health practitioners need to be sensitive to recognising and incorporating the specific health concerns experienced by lesbians, thereby responding effectively to their distinct needs. Effective healthcare should involve the co-production of treatment plans that reflect the needs and wishes of the individual and significant people in their lives, if appropriate. Central to this approach is providing a range of treatment options, including pharmacological interventions, thereby providing comprehensive evidence-based mental health care and treatment (Harvey \& Gumport 2015).

With the increasing visibility of lesbians and the growing evidence of their health concerns there is a need to ensure that education and continuing professional development (CPD) programmes reflect their specific needs and concerns. By incorporating lesbian health within CPD programmes, there is an opportunity to enhance knowledge and skills regarding issues such as cultural competence, equality and diversity and social inclusion (Sekoni et al. 2017). Healthcare undergraduate and education programmes need to ensure that the needs of LGBTQ+ people, including lesbians, are integrated within the curriculum thereby preparing the workforce of the future. There is a need to develop LGBTQ+ postgraduate education that enhances knowledge, skills and competence of health practitioners thus ensuring that service provision is evidence-based and responsive to the needs of LGBTQ+ people, including lesbians.

Arising from the findings of the current study, and the wider international research evidence, is an agenda that is reflective and responsive to the specific needs of lesbians (Cochrane \& Mays 2017). There is a need to grow and develop the research evidence regarding 
the health concerns and responses required by this population. There is an opportunity for nurse researchers to work with organisations and networks supporting lesbians to co-produce research studies that are reflective of their needs and concerns (Filipe et al.2017; Bowling et al. 2018). Further, LGBTQ+ researchers may collaborate nationally and internationally to conduct studies with larger samples to enable the identification of possible interventions and supports and undertake systematic evaluation studies.

\section{Limitations}

The current study builds on the evidence base regarding the mental health concerns and needs of lesbians in Ireland. The study only included women who had used mental health services, and this may be perceived as a limitation. The researchers acknowledge that diverse health service systems exist and the views and experiences of the participants in the current study may not be fully reflective of those internationally. The researchers attempted to recruit and include study participants from a diverse range of backgrounds and settings, however, this met with variable success and this limitation is acknowledged. However, this qualitative study offers a unique insight into the views and experiences of lesbian mental health service users and their psychosocial concerns and needs.

\section{CONCLUSION}

It is evident from the findings of this study and the wider research literature that lesbians have specific psychosocial support and care needs requiring access to mental health services for assessment, interventions, treatment and care. With the increasing visibility of sexual minority groups, including lesbians, there is a need to ensure that practitioners provide culturally competent and responsive healthcare. Mental health practitioners are in a position to work collaboratively with lesbians to identify and address their specific psychosocial concerns thereby seeking to reduce their health inequalities and improve their general health and wellbeing. Integrating the needs of lesbians and other sexual minority groups within nursing and 
other health education programmes will contribute to raising the awareness of their distinct needs and concerns within mental health services.

\section{IMPLICATIONS FOR NURSING PRACTICE}

Practitioners are in a position to work collaboratively with lesbians to identify and address their specific psychosocial concerns thereby seeking to reduce their health inequalities and improve their general health and well-being. Integrating the needs of lesbians and other sexual minority groups within nursing and other health education programmes will contribute to raising the awareness of their distinct needs and concerns within mental health services.

\section{Acknowledgements:}

The authors are grateful to the study participants who gave generously of their time. 


\section{REFERENCES}

Artiga, S., \& Hinton, E. (2019). Beyond health care: The role of social determinants in promoting health and health equity. Health, 20, 10.

Andersen, J. P., Hughes, T. L., Zou, C., \& Wilsnack, S. C. (2014). Lifetime victimization and physical health outcomes among lesbian and heterosexual women. PloS one, 9(7), e101939. doi.org/10.1371/journal.pone.0101939

Balsam, K. F., Beauchaine, T. P., Mickey, R. M., \& Rothblum, E. D. (2005). Mental health of lesbian, gay, bisexual, and heterosexual siblings: effects of gender, sexual orientation, and family. Journal of Abnormal Psychology, 114(3), 471. doi.org/10.1037/0021-843X.114.3.471

Balsam, KF, Molina, Y, Blayney, JA. (2015) Racial/ethnic differences in identity and mental health outcomes among young sexual minority women. Cultural Diversity \& Ethnic Minority Psychology,21(3), 380-390.

Bonomi, A. E., Anderson, M. L., Rivara, F. P., \& Thompson, R. S. (2007). Health outcomes in women with physical and sexual intimate partner violence exposure. Journal of Women's Health, 16(7), 987-997.

Bostwick, W. B., Boyd, C. J., Hughes, T. L., \& McCabe, S. E. (2010). Dimensions of sexual orientation and the prevalence of mood and anxiety disorders in the United States. American Journal of Public Health, 100(3), 468-475. doi.org/10.2105/AJPH.2008.152942 
Bostwick, W. B., Hughes, T. L., Steffen, A., Veldhuis, C. B., \& Wilsnack, S. C. (2019).

Depression and Victimization in a Community Sample of Bisexual and Lesbian Women: An Intersectional Approach. Archives of Sexual Behavior 48(1), 131-141.

Bowling, J., Dodge, B., Banik, S., Bartelt, E., Mengle, S., Guerra-Reyes, L., ... \& Anand, V. (2018). Social support relationships for sexual minority women in Mumbai, India: a photo elicitation interview study. Culture, Health \& Sexuality, 20(2), 183-200.

Caceres, B.A., Travers, J., Primiano, J.E., Luscombe, R.E., Dorsen, C. (2019) Provider and LGBT Individuals' Perspectives on LGBT Issues in Long-Term Care: A Systematic Review. The Gerontologist. doi: 10.1093/geront/gnz012.

Clarke, V. \& Braun, V. (2017) Thematic analysis. The Journal of Positive Psychology 12(3), $297-298$.

Cochran, S.D. \& Mays, V.M. (2017) Advancing the LGBT Health Research Agenda: Differential Health Trends Within the Lesbian, Gay, and Bisexual Populations American Journal of Public Health 107, 497- 498.

D'Emilio, J. (2019) The history of sexuality: An assessment of the state of the field. History and Theory 58(1), 126-134. doi.org/10.1111/hith.12103

de Lira, A. N., \& de Morais, N. A. (2018). Resilience in lesbian, gay, and bisexual (LGB) populations: An integrative literature review. Sexuality Research and Social Policy, 15(3), 272-282. 
Drabble, L., Midanik, L. T., \& Trocki, K. (2005). Reports of alcohol consumption and alcohol-related problems among homosexual, bisexual and heterosexual respondents: results from the 2000 National Alcohol Survey. Journal of Studies on Alcohol, 66(1), 111-120. doi.org/10.15288/jsa.2005.66.111

Drabble, L., Trocki, K. F., Hughes, T. L., Korcha, R. A., \& Lown, A. E. (2013). Sexual orientation differences in the relationship between victimization and hazardous drinking among women in the National Alcohol Survey. Psychology of Addictive Behaviors, 27(3), 639.

Dworkin, E. R., Cadigan, J., Hughes, T., Lee, C., \& Kaysen, D. (2018). Sexual identity of drinking companions, drinking motives, and drinking behaviors among young sexual minority women: An analysis of daily data. Psychology of Addictive Behaviors, 32(5), 540.

Edwards, K. M., Sylaska, K. M., \& Neal, A. M. (2015). Intimate partner violence among sexual minority populations: A critical review of the literature and agenda for future research. Psychology of Violence, 5(2), 112.

Filipe, A., Renedo, A., \& Marston, C. (2017). The co-production of what? Knowledge, values, and social relations in health care. PLoS Biology, 15(5), e2001403.

Flanagan, S. M., \& Hancock, B. (2010). 'Reaching the hard to reach'-lessons learned from the VCS (voluntary and community Sector). A qualitative study. BMC Health Services Research, 10(1), 92 . 
Friedman, M. S., Marshal, M. P., Guadamuz, T. E., Wei, C., Wong, C. F., Saewyc, E. M., \& Stall, R. (2011). A meta-analysis of disparities in childhood sexual abuse, parental physical abuse, and peer victimization among sexual minority and sexual nonminority individuals. American Journal of Public Health, 101(8), 1481-1494.

Government Equality Office (2018). National LGBT Survey. London: HMSO.

Government of Ireland. (2006). A vision for change: Report of the expert group on mental health policy. Dublin: Government of Ireland.

Graneheim, U.H., Lindgren, B.M. \& Lundman, B. (2017) Methodological challenges in qualitative content analysis: A discussion paper. Nurse Education Today 56, 29-34. doi: 10.1016/j.nedt.2017.06.002

Hafeez, H., Zeshan, M., Tahir, M. A., Jahan, N., Naveed, S. (2017) Health care disparities among lesbian, gay, bisexual, and transgender youth: A literature review. Cureus 9(4). doi: $10.7759 /$ cureus. 1184

Harvey, A. G., \& Gumport, N. B. (2015). Evidence-based psychological treatments for mental disorders: Modifiable barriers to access and possible solutions. Behaviour Research and Therapy, 68, 1-12.

Health Service Executive (2016) Psychology Briefing Paper for the Primary Care Division. Dublin: HSE. 
Hickson, F., Davey, C., Reid, D., Weatherburn, P., Bourne, A. (2016) Mental health inequalities among gay and bisexual men in England, Scotland and Wales: A large community-based cross-sectional survey. Journal of Public Health 39(2), 266-273. doi: 10.1093/pubmed/fdw021

Hughes, T., Szalacha, L. A., \& McNair, R. (2010) Substance abuse and mental health disparities: Comparisons across sexual identity groups in a national sample of young Australian women. Social Science \& Medicine 71(4), 824-831. doi:

10.1016/j.socscimed.2010.05.009

Institute of Medicine Staff (1999). Lesbian Health: Current Assessment and Directions for the Future. Washington: National Academies Press.

Jessup, M. A., \& Dibble, S. L. (2012). Unmet mental health and substance abuse treatment needs of sexual minority elders. Journal of Homosexuality, 59(5), 656-674.

Kelleher, C. (2009). Minority stress and health: Implications for lesbian, gay, bisexual, transgender, and questioning (LGBTQ) young people. Counselling Psychology Quarterly, 22(4), 373-379.

Kertzner, R. M., Meyer, I. H., Frost, D. M., \& Stirratt, M. J. (2009). Social and psychological weil-being in lesbians, gay men, and bisexuals: The effects of race, gender, age, and sexual identity. American Journal of Orthopsychiatry, 79(4), 500-510. 
Kwon, P. (2013). Resilience in lesbian, gay, and bisexual individuals. Personality and Social Psychology Review, 17(4), 371-383.

LaVaccare, S., Diamant, A.L., Friedman, J., Singh, K.T., Baker, J.A., Rodriguez, T.A., Cohen, S.R., Dary, F.Y. and Pregler, J. (2018). Healthcare experiences of underrepresented lesbian and bisexual women: A focus group qualitative study. Health Equity, 2(1), pp.131138.

Lea, T., de Wit, J., \& Reynolds, R. (2014). Minority stress in lesbian, gay, and bisexual young adults in Australia: Associations with psychological distress, suicidality, and substance use. Archives of Sexual Behavior, 43(8), 1571-1578.

Lincoln, Y.S., \& Guba, E.G. (1985) Naturalistic Inquiry. California: Sage.

Livingston, N. A., Berke, D. S., Ruben, M. A., Matza, A. R., \& Shipherd, J. C. (2019). Experiences of trauma, discrimination, microaggressions, and minority stress among traumaexposed LGBT veterans: Unexpected findings and unresolved service gaps. Psychological Trauma: Theory, Research, Practice, and Policy.

Lyons, A. (2015). Resilience in lesbians and gay men: A review and key findings from a nationwide Australian survey. International Review of Psychiatry, 27(5), 435-443.

McCabe, S. E., Hughes, T. L., Bostwick, W. B., West, B. T., \& Boyd, C. J. (2009). Sexual orientation, substance use behaviors and substance dependence in the United States. Addiction, 104(8), 1333-1345. doi.org/10.1111/j.1360-0443.2009.02596.x 
McCann, E. \& Brown, M. (2018) The inclusion of LGBT+ health issues within undergraduate healthcare education and professional training programmes: A systematic review. Nurse Education Today 64, 204-214. doi: 10.1016/j.nedt.2018.02.028

McCann, E. \& Brown, M. (2019a) The mental health needs and concerns of older people who identify as LGBTQI+: A narrative review of the international literature. Journal of Advanced Nursing. https://doi.org/10.1111/jan.14193

McCann, E., \& Brown, M. (2019b). Education and practice developments: Addressing the psychosocial concerns and support needs of LGBT+ people. Nurse Education Today, 82, 1520.

Meneguzzo, P., Collantoni, E., Gallicchio, D., Busetto, P., Solmi, M., Santonastaso, P., \& Favaro, A. (2018). Eating disorders symptoms in sexual minority women: A systematic review. European Eating Disorders Review, 26(4), 275-292.

Merner, B., Hill, S., Colombo, C., Xafis, V., Gaulden, C. M., Graham-Wisener, L., ... \& Chmielewski, R. (2019). Consumers and health providers working in partnership for the promotion of person-centred health services: a co-produced qualitative evidence synthesis. Cochrane Database of Systematic Reviews, (2).

Meyer, I. H. (2003). Prejudice, social stress, and mental health in lesbian, gay, and bisexual populations: conceptual issues and research evidence. Psychological Bulletin, 129(5), 674697. 
Meyer, I. H. (2015). Resilience in the study of minority stress and health of sexual and gender minorities. Psychology of Sexual Orientation and Gender Diversity, 2(3), 209.

Moore, L., Britten, N., Lydahl, D., Naldemirci, Ö., Elam, M., \& Wolf, A. (2017). Barriers and facilitators to the implementation of person-centred care in different healthcare contexts. Scandinavian Journal of Caring Sciences, 31(4), 662-673.

Noble, H. \& Smith, J. (2015) Issues of validity and reliability in qualitative research. Evidencebased Nursing 18(2), 34-35. doi.org/10.1136/eb-2015-102054

Pyra, M., Weber, K.M., Wilson, T.E., Cohen, J., Murchison, L. Goparaju, L. Golub, E.T., \& Cohen, M.H. (2014). Sexual Minority Women and Depressive Symptoms Throughout Adulthood. American Journal of Public Health 104(12), e83-e90.

QSR International (2015). NVivo qualitative data analysis software; QSR International Pty Ltd. Version 11.

Rowe, D., Ng, Y. C., O’Keefe, L., \& Crawford, D. (2017). Providers' Attitudes and Knowledge of Lesbian, Gay, Bisexual, and Transgender Health. Federal Practitioner, 34(11), 28.

Sabin, JA, Riskind, RG, Nosek, BA (2015) Health care providers' implicit and explicit attitudes toward lesbian women and gay men. American Journal of Public Health, 105(9), $1831-1841$. 
Schneeberger, A. R., Dietl, M. F., Muenzenmaier, K. H., Huber, C. G., \& Lang, U. E. (2014). Stressful childhood experiences and health outcomes in sexual minority populations: a systematic review. Social Psychiatry and Psychiatric Epidemiology, 49(9), 1427-1445.

Sekoni, A. O., Gale, N. K., Manga-Atangana, B., Bhadhuri, A., \& Jolly, K. (2017). The effects of educational curricula and training on LGBT-specific health issues for healthcare students and professionals: a mixed-method systematic review. Journal of the International AIDS Society, 20(1), 21624.

Simoni, J. M., Smith, L., Oost, K. M., Lehavot, K., \& Fredriksen-Goldsen, K. (2017). Disparities in physical health conditions among lesbian and bisexual women: A systematic review of population-based studies. Journal of Homosexuality, 64(1), 32-44.

Smith, R.W., Altman, J.K., Meeks, S., Hinrichs, K.L. (2018). Mental health care for LGBT older adults in long-term care settings: Competency, training, and barriers for mental health providers. Clinical Gerontologist, 1-6. doi: 10.1080/07317115.2018.1485197.

Snyder, M. (2019). Health Care Experiences of Lesbian Women: A Metasynthesis. Advances in Nursing Science, 42(1), E1-E21.

Soinio, J. I. I., Paavilainen, E. M., \& Kylmä, J. P. O. (2019). Lesbian and Bisexual Women's Experiences of Health Care:“Do not say, 'husband', say,'spouse'”. Journal of Clinical Nursing. doi.org/10.1111/jocn.15062 
Steele, L. S., Daley, A., Curling, D., Gibson, M. F., Green, D. C., Williams, C. C., \& Ross, L. E. (2017). LGBT identity, untreated depression, and unmet need for mental health services by sexual minority women and trans-identified people. Journal of Women's Health, 26(2), 116127.

Szalacha, L. A., Hughes, T. L., McNair, R., \& Loxton, D. (2017). Mental health, sexual identity, and interpersonal violence: Findings from the Australian longitudinal Women's health study. BMC Women's Health, 17(1), 94.

Artiga, S., \& Hinton, E. (2019). Beyond health care: The role of social determinants in promoting health and health equity. Health, 20, 10.

Toomey, R. B., Ryan, C., Diaz, R. M., \& Russell, S. T. (2018). Coping With Sexual Orientation-Related Minority Stress. Journal of homosexuality, 65(4), 484-500.

Trocki, K. F., Drabble, L. A., \& Midanik, L. T. (2009). Tobacco, marijuana, and sensation seeking: comparisons across gay, lesbian, bisexual, and heterosexual groups. Psychology of Addictive Behaviors, 23(4), 620. doi.org/10.1037/a0017334

Veldhuis, C. B., Hughes, T. L., Drabble, L., Wilsnack, S. C., Riggle, E. D. \& Rostosky, S. S. (2019). Relationship status and drinking-related outcomes in a community sample of lesbian and bisexual women. Journal of Social and Personal Relationships, 36(1), 244-268.

Voss, M. J. (2018). Contesting Sexual Orientation and Gender Identity at the UN Human Rights Council. Human Rights Review 19(1), 1 22. doi.org/10.1007/s12142-017-0483-1 
Wahlbeck, K. (2015). Public mental health: The time is ripe for translation of evidence into practice. World Psychiatry, 14(1), 36-42.

Willams Institute (2016). LGBT Demographic Data Interactive.

Los Angeles, CA: The Williams Institute, UCLA School of Law.

World Health Organization. (2013). Addressing the causes of disparities in health service access and utilization for lesbian, gay, bisexual and transgender (LGBTQ) persons. WHO, Geneva.

Younas, A. (2019). Lesbian-, gay-, bisexual-and transgender-related inequalities within nursing: A neglected research area. Journal of Advanced Nursing. doi.org/10.1111/jan.14005 


\begin{tabular}{|c|c|c|c|c|c|c|c|}
\hline Participant & Diagnosis & Interventions received & Service & Participant & Diagnosis & Interventions received & Service \\
\hline P1 & Depression & Medication & Outpatient & P10 & $\begin{array}{l}\text { Eating disorder } \\
\text { Personality disorder } \\
\text { Sleep disorder }\end{array}$ & $\begin{array}{l}\text { CBT } \\
\text { Medication }\end{array}$ & Outpatient/inpatient \\
\hline P2* & $\begin{array}{l}\text { Anxiety } \\
\text { Depression }\end{array}$ & Medication & Outpatient & P11 & $\begin{array}{l}\text { Anxiety } \\
\text { Bipolar disorder } \\
\text { Depression } \\
\text { Eating disorder }\end{array}$ & $\begin{array}{l}\text { CBT } \\
\text { Medication } \\
\text { Mindfulness }\end{array}$ & Outpatient/inpatient \\
\hline P3 & PTSD & Medication & Outpatient & P12* & $\begin{array}{l}\text { Anxiety } \\
\text { Depression }\end{array}$ & $\begin{array}{l}\text { CBT } \\
\text { Medication }\end{array}$ & Outpatient \\
\hline P4 & Depression & $\begin{array}{l}\text { CBT } \\
\text { Medication }\end{array}$ & Outpatient & P13 & $\begin{array}{l}\text { Anxiety } \\
\text { Depression }\end{array}$ & $\begin{array}{l}\text { CBT } \\
\text { Medication }\end{array}$ & Outpatient \\
\hline P5 & Anxiety & $\mathrm{CBT}$ & Outpatient & P14 & $\begin{array}{l}\text { Depression } \\
\text { Eating disorder }\end{array}$ & Medication & Outpatient \\
\hline P6 & Depression & $\begin{array}{l}\text { CBT } \\
\text { Family therapy } \\
\text { Medication }\end{array}$ & Outpatient/inpatient & P15 & Schizophrenia & Medication & Outpatient \\
\hline P7 & Depression & Medication & Outpatient & P16 & Depression & $\begin{array}{l}\text { CBT } \\
\text { Medication }\end{array}$ & Outpatient \\
\hline P8* & $\begin{array}{l}\text { Anxiety } \\
\text { Bipolar disorder } \\
\text { Depression } \\
\text { Eating disorder }\end{array}$ & Medication & Outpatient/inpatient & P17* & $\begin{array}{l}\text { Depression } \\
\text { Gender Identity Disorder }\end{array}$ & Medication & Outpatient \\
\hline P9 & Depression & $\begin{array}{l}\text { CBT } \\
\text { ECT } \\
\text { Medication }\end{array}$ & Outpatient/inpatient & P18* & $\begin{array}{l}\text { Anxiety } \\
\text { Depression } \\
\text { Eating disorder }\end{array}$ & $\begin{array}{l}\text { Counselling } \\
\text { Medication }\end{array}$ & Inpatient \\
\hline
\end{tabular}




\begin{tabular}{|c|c|c|c|c|c|c|c|}
\hline Participant & Diagnosis & Interventions received & Service & Participant & Diagnosis & Interventions received & Service \\
\hline P19 & Eating disorder & $\begin{array}{l}\text { Medication } \\
\text { Family therapy }\end{array}$ & Outpatient & P31 & $\begin{array}{l}\text { Depression } \\
\text { Eating disorder } \\
\text { PTSD }\end{array}$ & Medication & Outpatient/inpatien \\
\hline $\mathbf{P 2 0}$ & Depression & $\begin{array}{l}\text { CBT } \\
\text { Medication }\end{array}$ & Outpatient & P32 & $\begin{array}{l}\text { Depression } \\
\text { Eating disorder } \\
\text { Personality disorder }\end{array}$ & Medication & Outpatient/inpatien \\
\hline P21 & Depression & Medication & Outpatient & P33 & $\begin{array}{l}\text { Anxiety } \\
\text { Depression }\end{array}$ & Medication & Outpatient/inpatien \\
\hline P22* & $\begin{array}{l}\text { OCD } \\
\text { PTSD } \\
\text { Sleep disorder }\end{array}$ & Medication Mindfulness & Outpatient/inpatient & P34 & $\begin{array}{l}\text { Anxiety } \\
\text { Depression }\end{array}$ & Medication & Outpatient \\
\hline $\mathbf{P 2 3}$ & Schizophrenia & Medication & Outpatient/inpatient & P35* & Substance misuse & Medication & Outpatient/inpatien \\
\hline SR24 & Gender Identity Disorder & $\begin{array}{l}\text { CBT } \\
\text { Family therapy } \\
\text { Medication }\end{array}$ & Outpatient & P36 & $\begin{array}{l}\text { Depression } \\
\text { Eating disorder } \\
\text { Gender Identity Disorder }\end{array}$ & $\begin{array}{l}\text { CBT } \\
\text { Family Therapy } \\
\text { Medication }\end{array}$ & Outpatient/inpatien \\
\hline P25 & $\begin{array}{l}\text { Depression } \\
\text { Eating disorder } \\
\text { OCD }\end{array}$ & $\begin{array}{l}\text { Medication } \\
\text { Mindfulness } \\
\text { Music therapy }\end{array}$ & Outpatient & P37 & $\begin{array}{l}\text { Depression } \\
\text { Gender Identity Disorder }\end{array}$ & Medication & Inpatient \\
\hline P26 & Depression & CBT & Outpatient & P38 & $\begin{array}{l}\text { Depression } \\
\text { Eating disorder } \\
\text { Self-injury }\end{array}$ & $\begin{array}{l}\text { CBT } \\
\text { Counselling Medication }\end{array}$ & Outpatient \\
\hline P27 & Depression & $\begin{array}{l}\text { Medication } \\
\text { Mindfulness }\end{array}$ & Outpatient & P39 & $\begin{array}{l}\text { Anxiety } \\
\text { Depression }\end{array}$ & Counselling Medication & Outpatient \\
\hline P28 & Depression & $\begin{array}{l}\text { Art therapy } \\
\text { Medication }\end{array}$ & Outpatient & P40 & $\begin{array}{l}\text { Depression } \\
\text { OCD }\end{array}$ & Counselling Medication & Outpatient \\
\hline
\end{tabular}




\begin{tabular}{|l|l|l|l|l|l|l|}
\hline P29 & $\begin{array}{l}\text { Anxiety } \\
\text { Depression }\end{array}$ & Medication & Outpatient & P41 & $\begin{array}{l}\text { Bipolar disorder } \\
\text { Depression }\end{array}$ \\
\hline P30 & Depression & $\begin{array}{l}\text { CBT } \\
\text { Mindfulness }\end{array}$ & Outpatient & & \\
Medication
\end{tabular}

* represents people who also took part in a face-to-face interview $(n=7)$ 